\title{
Research on the Integration Development Mode of China's Media Industry and Capital Market
}

\author{
Yutong $\mathrm{Miao}^{1}$ \\ Major: Communication \\ ${ }^{1}$ Institution: University of California, Santa Barbara \\ City: Santa Barbara, CA \\ Country: U.S. \\ Postal Code: 93117
}

\begin{abstract}
With the rapid development of Internet and digital technology, China's media industry has been developing rapidly in this context, but at the same time, it also exposed some practical problems such as the shortage of funds. The effective integration with the capital market is the future development trend. Therefore, this paper establishes the research on the integration development mode of China's media industry and capital market. This paper makes an in-depth study on the current media industry and capital market. Through this study, it is believed that the current media industry in China has reached the bottleneck of development, and the shortage of funds has restricted the sustainable development of enterprises. The capital market is also optimistic about the market prospect of media industry, but it is subject to the current open policy and market environment. In view of this situation, this paper analyzes the structure of the media industry and the main forms of the extra industry capital entering the media industry. It is believed that the biggest reason for the media industry's demand for capital comes from the fact that many media enterprises have changed from the original public institutions into self-financing enterprises without the financial support of the government. In this paper, combined with the main characteristics of China's media industry, as well as the current capital market environment, integrated with advanced financial management concepts, put forward the development of media financing mode with Chinese characteristics, which makes up for the shortcomings of the current media financing mode.
\end{abstract}

\section{Introduction}

The media industry is the product of the development of media, and the media is the carrier of information dissemination. Specifically, media industry refers to the industrial group composed of media entities that disseminate various information and knowledge [1-3]. The media industry not only depends on the sales of products to obtain the corresponding profit return, but also its advertising revenue is one of the main incomes of the current media industry, which means that whether the media industry can attract the attention of the audience is its main economic value. From the perspective of industrial structure, media industry is an industrial system composed of many subsystems. These subsystems are based on information services and are the core business of the media industry [4-6].

With the rapid development of China's economy, the demand of enterprises and individuals for information services is increasing rapidly. In this context, the development of China's media industry has also made remarkable achievements, especially the rapid development of new media industry, which promotes the restructuring and transformation of traditional media enterprises [7-8]. At the same time, the media enterprises have basically established the dominant position of the market in China's market economy, and the operation mechanism of media enterprises is gradually in line with international standards. However, compared with the development of foreign media industry, China's media industry is still at a relatively backward level. Most media enterprises in China have not established modern enterprise management system, which leads to low level of internal management and nonstandard market development. Therefore, to give full play to the role of capital market, media enterprises can become stronger and stronger [9-10].

This paper deeply studies the structural characteristics of China's media industry segmentation market, and understands that book publishing and television advertising account for the main proportion of China's media industry, especially with the rapid development of television and other video media, its advertising revenue has become the main source of income of the current media industry. Based on the policy reform, most of the traditional media enterprises have changed from public institutions to enterprise systems. Under the pressure of 
operation, there are problems such as shortage of funds. Therefore, this paper puts forward the research on the integration development mode of China's media industry and capital market, hoping to promote the capital operation of China's media industry through the research on the characteristics of media industry and the mode of integration with outside industry capital. In view of the actual demand, this paper makes an in-depth study on the reasons for the combination of the media industry and the capital market. The analysis shows that the development of the media industry is restricted by the shortage of funds. In view of this situation, this paper puts forward a media financing mode based on Chinese characteristics, which has been improved on the basis of the current major media industry financing mode, that is, better avoiding the risk, but also optimizing the management structure after financing, which helps the development of enterprises.

\section{Definition of Media Industry and Capital}

\subsection{Definition of Media Industry}

The term "media industry" originated in the United States and gradually accepted by all countries in the world. Media industry is the economic embodiment of media in a certain social environment. Only when the media industry is pushed to the market can it be called media industry. There is no unified understanding of the definition of media industry in domestic theoretical circles. At present, the media is the mainstream of the information industry, which covers the fields of information production, processing and dissemination. The media industry is a typical information service industry. At the same time, the information source of the media has strong cultural and humanized characteristics, so the media industry is also a part of cultural undertakings. As a social industry system, media industry has a wide range of contents, including newspapers, books, television, and the rapid rise of Internet video. Therefore, the media industry can be positioned as the marginal industry of cultural industry and information service industry.

\subsection{Meaning of Capital}

Capital is the value that can bring surplus value. No matter what form of capital, it must have value. In the actual material production process, only capital can realize value increment. Therefore, capital can bring value-added, which is the definition of capital connotation. In the early stage of enterprise development, the concept of capital is always limited to the resources owned by the enterprise, including various properties. This reduces the scope of capital to internal, tangible capital. With the development of economy, the concept of traditional capital has been broken. The scope of capital is constantly expanding, including valuable resources such as technical capital and brand capital. Capital emphasizes the nature of its resources and generally refers to all tangible and intangible values that can be used as economic resources of enterprises.

\section{Structural Analysis of China's Media Industry Segmentation Market}

According to relevant reports, global entertainment and media have entered a stable development stage since 2010. By 2030, the industry's compound annual growth rate will reach $8.2 \%$, and the market size will reach 3.9 trillion US dollars. The Asia Pacific region will continue to be the fastest growing region in the industry. At present, Chinese mainland has surpassed Japan and has become the largest entertainment media market in the Asia Pacific region. In such a fast-developing industry, its capital operation should be carried out at a faster pace. This paper investigates and analyzes the current market structure of the media industry in China, and makes a statistical table of its basic share, as shown in Table 1. According to the results of Table 1, at present, China's media industry is still dominated by book publishing, followed by TV advertising and mobile phone SMS.

Table 1: market structure of China's media industry.

\begin{tabular}{|c|c|c|c|}
\hline Segmentation industry & Proportion (\%) & Segmentation industry & Proportion (\%) \\
\hline Audio visual products & 1.2 & Broadcast advertisement & 1.8 \\
\hline Film & 1.6 & Periodical advertisement & 0.3 \\
\hline Periodical distribution & 7.5 & Television advertising & 10.6 \\
\hline Newspaper distribution & 5.1 & Newspaper advertisement & 7.1 \\
\hline Book publishing & 38.6 & Game & 2.3 \\
\hline Cable TV charges & 4.3 & SMS & 9.9 \\
\hline Advertising agency & 9.7 & & \\
\hline
\end{tabular}

\section{Discussion}

\subsection{An Analysis of the Causes of Capital Operation in China's Media Industry}

In developed countries, media has become one of the industries with large scale and rich profits. However, after years of development, foreign media market has been relatively saturated. Due to the rapid growth of advertising revenue, the average annual growth rate of China's media industry is far greater than that of GDP in the same period, which has great attraction to foreign investment. According to the survey results, in Figure 1, the income of media industry in developed countries accounts for about 
$3.5 \%$ of GDP, while that of China is less than $1.5 \%$ of GDP. Various data show that China's media industry will become a very attractive investment industry.

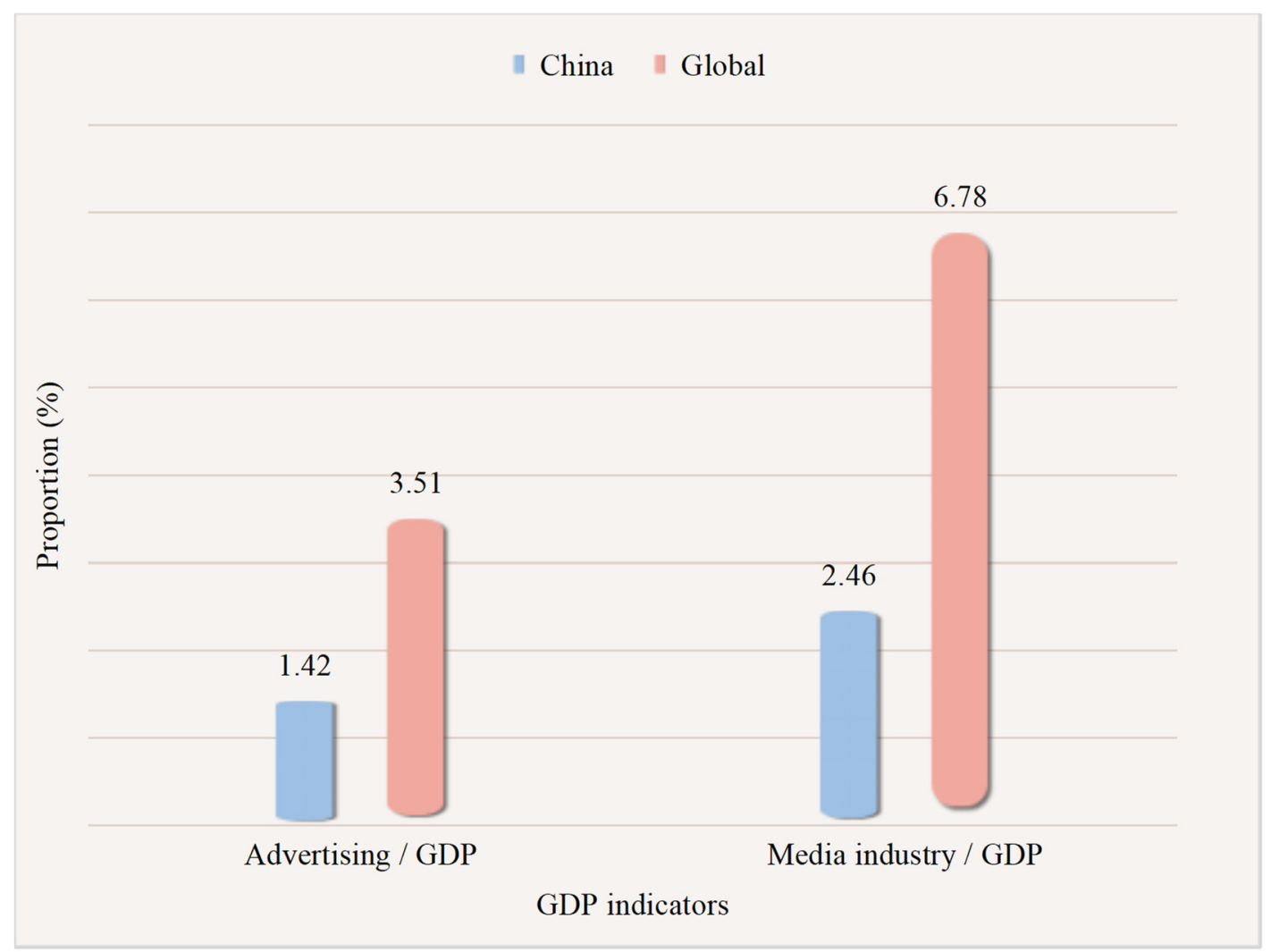

Figure 1: Comparison of GDP proportion of China's media industry and global media industry in 2019

The media are generally faced with the plight of insufficient development funds and need new funds, especially venture capital. In recent years, the economic benefit of media industry is remarkable, but the fund is still short. According to the survey results in Figure 2, the media industry is still dominated by independent operation and financial allocation. Among them, advertising revenue accounted for $78.6 \%$ of all revenue, which accounted for the highest proportion of business. The second is the development fund supported by the state, accounting for $16.7 \%$, However, the proportion of non-industry capital inflow was only $2.8 \%$, and other capital accounted for $1.9 \%$. This fully shows that in the existing media industry, the proportion of capital market integration is relatively low, which is mainly caused by various reasons, including relevant policies and market environment, which further shows the plight of the current media industry for lack of funds. 


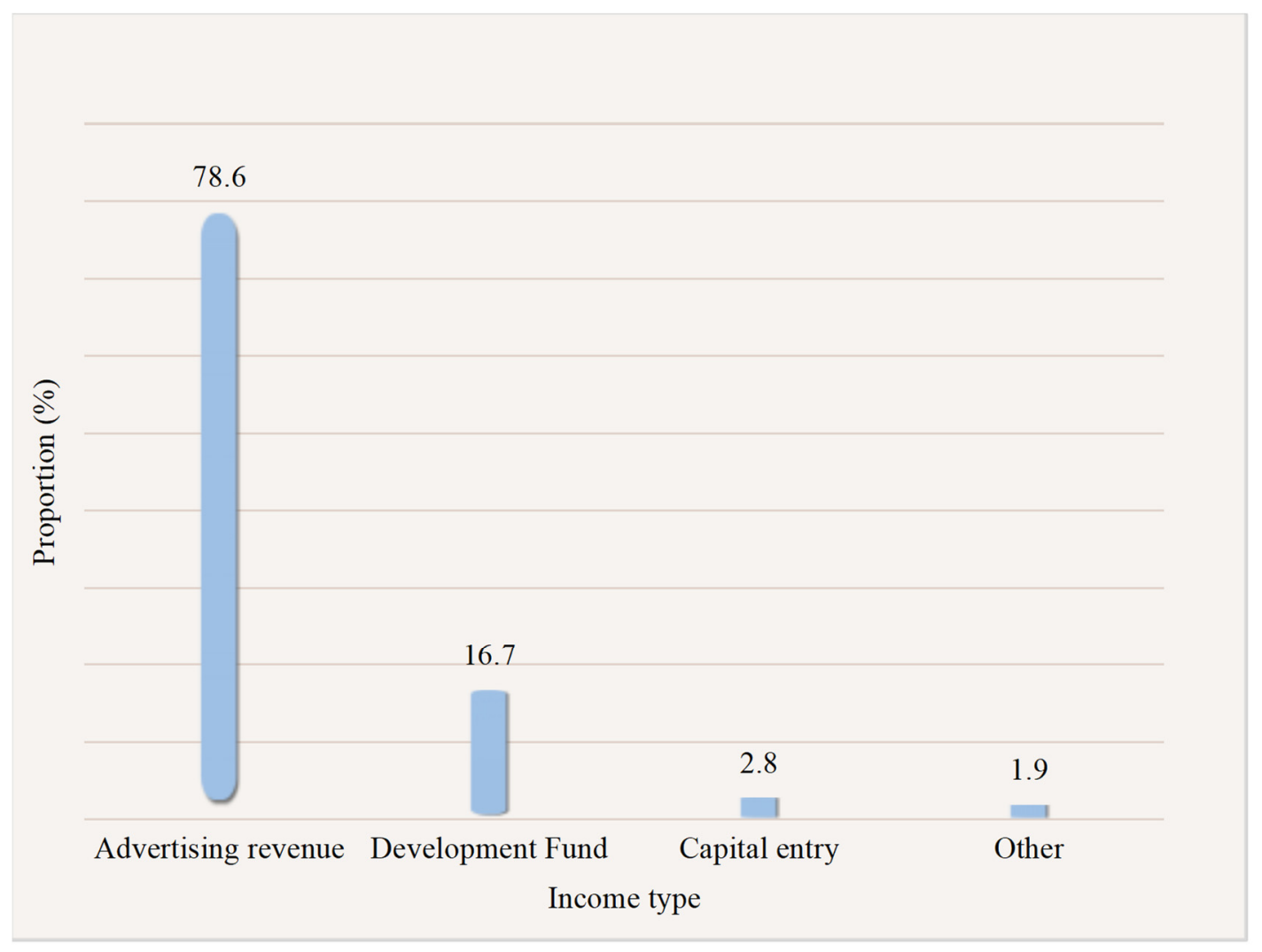

Figure 2: Analysis on the proportion of consumers' response to different promotion strategies

\subsection{Reasons for the Combination of Media Industry and Capital Market}

In the past, the media only existed as an ideological tool and was supported by the state. However, with the establishment and development of China's market economy system, the media industry, as a part of the information industry, will inevitably reflect the function of industrialization in the market economy, which attracts the attention of operators and researchers. In the information age of rapid economic development, the media industry is facing inevitable challenges. Especially after the media separated from the sources of funds allocated by the state finance, they entered the market and were responsible for their own profits and losses. From the development trend of the media industry, in order to adapt to the evolution of the industry and the acceleration of competition, the major media enterprises have established a comprehensive media group. The scale of capital operation has been expanded rapidly through mergers and acquisitions.

\subsection{Main Ways of Capital Injection into Media Industry}

There are several ways for capital to enter the media industry

(1) Cooperative operation. In exchange for the transfer of advertising management rights and publishing rights of news media within a certain period of time, and share the profits of advertising operation rights and publishing rights.

(2) Through the stock market and other capital operation means to penetrate into the media industry. Most of the companies that enter the media in this way are listed companies. These listed companies are generally companies with stable main business and sufficient funds.

(3) Get marketing rights. This method is mainly adopted by some media organizations. The media content obtained by this way is usually marginal content such as economy and entertainment.

\subsection{Main Characteristics of Media Investment}

(1) The media investment boom will continue. Because the media and the Internet are different, the investment media will not become "bubble" like investing in the Internet. In addition, the government's liberalization of the media industry must be limited and gradual, which promotes the continuous investment of funds into the media industry.

(2) Investors are watching the impact of the media. Media has brand effect, some investors do not expect to profit from the media itself, but hope to use the influence of media to profit from other related industries.

(3) Gradually from the "implicit cooperation" based investment model to the use of capital market access and exit mechanism for media investment.

(4) Some media investors aim to promote listing. Through the media investment to improve its business performance, and in the listing, application can be injected into the media business assets. 


\subsection{Developing Media Financing Mode with Chinese Characteristics}

It can be seen from the above discussion that more and more investors are keen on the market-oriented financing mode. The media industry has set off a boom in the capital market, but the bank led financing model has not been more favored. The analysis shows that, considering the inherent system of domestic media institutions, including the confusion of property rights structure, such development will not only solve the immediate problems, but also make the future development path more chaotic. In addition, media organizations should see that in addition to the operation of the stock market, they can also use financial leverage for financing. Generally speaking, under the premise of ensuring that the government controls the news and public opinion, we should develop the media industry financing mode with Chinese characteristics, that is, debt financing is the main mode, equity financing and cooperative investment are auxiliary. Although listed financing is equity financing, it can not only maintain the dominant position of debt financing, but also maximize the organizational power of equity financing in raising social idle funds. It is a diversified financing mode.

\section{Conclusions}

In this paper, in the research of the development mode of the integration of media industry and capital market, the main mode of the current media industry external capital integration is studied in depth. At present, there are some problems in the media industry in China, such as business concentration, unreasonable income structure, lack of modern management system and so on. After transforming from traditional institutions into self-financing enterprises, many media enterprises have exposed the problem of capital shortage in the absence of follow-up financial support. The research on the integration development mode of China's media industry and capital market proposed in this paper, to a certain extent, makes up for the main problems in the integration mode of China's media industry and capital market, and makes contributions to the improvement and optimization of media financing mode. The analysis shows that under the background of the rapid development of the Internet and digital technology, the media industry has a good development prospect, but the existing management mode and business structure model have brought certain risks to the long-term development of enterprises, and the way of capital intervention can improve the business model of enterprises, which is more conducive to the long-term development of the media industry.

\section{References}

1. Lugmayr, A. (2017). Information systems research in the media industry. Electronic Markets, 27(1), 1-2.

2. Dekoulou, P., \& Trivellas, P. (2017). Organizational structure, innovation performance and customer relationship value in the greek advertising and media industry. Journal of business \& industrial marketing, 32(3), 385-397.

3. Sarigianni, C., Thalmann, S., \& Manhart, M. (2015). Knowledge risks of social media in the financial industry. International Journal of Knowledge Management, 11(4), 19-34.

4. Yulianto, M., Girsang, A. S., \& Rumagit, R. Y. (2018). Business intelligence for social media interaction in the travel industry in indonesia. Journal of Intelligence Studies in Business, 8(2), 72-79.

5. Hussain, S. B. (2015). The impact of social media within the sporting industry. Problems \& Perspectives in Management, 13(4), 223-229.

6. Shih, C. H., Wu, C. C., \& Yang, T. H. (2018). Diversification, internal capital market, and information advantage. Universal Journal of Management, 6(9), 318-339.

7. Lee, L. F., Hutton, A. P., \& Shu, S. (2015). The role of social media in the capital market: evidence from consumer product recalls. Journal of Accounting Research, 53(2), 367-404.

8. Chordia, T., Goyal, A., Nozawa, Y., Subrahmanyam, A., \& Tong, Q. (2017). Are capital market anomalies common to equity and corporate bond markets? an empirical investigation. Journal of Financial and Quantitative Analysis, 52(04), 1301-1342.

9. Miller, G. (2017). Us capital market access on the rise. Fairplay, 388(6902), 16-17.

10. Dima, B., Barna, F., \& Nachescu, M. L. (2018). Does rule of law support the capital market? Ekonomska Istraivanja / Economic Research, 31(1), 461-479. 